\title{
A NÃO REDUÇÃO DA EPISTEMOLOGIA ÀS CIÊNCIAS COGNITIVAS E A QUESTÃO DO DISJUNTIVISMO
}

\author{
THE NON-REDUCTION OF EPISTEMOLOGY TO COGNITIVE SCIENCES AND THE ISSUE OF \\ DISJUNCTIVISM
}

Paulo Andrade Vitória*

\section{RESUMO}

No presente artigo abordo a questão da redução da epistemologia às ciências cognitivas, explorando o debate entre Burge e McDowell sobre o disjuntivismo epistemológico. Dessa maneira, começo apontando a tese da indistinguibilidade que afirma que existe um denominador comum entre uma experiência perceptiva verídica e uma experiência perceptiva enganosa. Veremos que essa tese motiva um argumento cético. Em seguida apresento a posição disjuntivista de McDowell que afirma que experiências verídicas e não verídicas diferem em valor cognitivo. Mostro as críticas de Burge ao disjuntivismo de McDowell, e a sua tese de que a experiência perceptiva deve ser tratada pelas ciências cognitivas. Depois disso, mostro a resposta de McDowell a Burge de que o caráter epistêmico da experiência difere do caráter descritivo das ciências cognitivas. Por fim, digo por que a epistemologia não pode ser reduzida às ciências cognitivas.

PALAVRAS CHAVES: Burge. Ciências cognitivas. Disjuntivismo. Epistemologia. McDowell.

\section{ABSTRACT}

In this pappers I address the issue of reducing epistemology to the cognitive sciences, exploring the debate between Burge and McDowell about epistemological disjunctivism. In this way, I begin by pointing out the indistinguishable thesis that states that there is a common denominator between a true perceptual experience and a misleading perceptual experience. I will show that this thesis motivates a skeptical argument. Then I present McDowell's disjunctivist position, which states that although they have a common denominator, veridical and non-veridical experiences differ in cognitive value. I show Burge's criticisms of McDowell's disjunctivism, and his thesis that the perceptual experience must be addressed by the cognitive sciences. After that, I show McDowell's response to Burge that the epistemic character of experience differs from the descriptive character of the cognitive sciences. Finally, I say why epistemology cannot be reduced to epistemology.

KEYWORDS: Burge. Cognitive sciences. Disjunctivism. Epistemology. McDowell.

\footnotetext{
* Doutorando de filosofia pela UFMG. Professor de filosofia na PUC Minas e ISTA. E-mail: pauloandradebh@gmail.com.
} 


\section{INTRODUÇÃO}

McDowell e Tyler Burge recentemente se engajaram em um debate sobre a posição disjuntivista acerca da experiência perceptiva. A tese defendida pelos disjuntivistas é de que não existe nenhum denominador comum entre uma experiência perceptiva verídica e uma experiência perceptiva enganosa. ${ }^{1}$ Vamos considerar a experiência perceptiva verídica aquela em que as coisas se apresentam ao sujeito realmente como são. Neste caso, se X tem uma experiência visual de um tomate, então X realmente está diante de um tomate. Por outro lado, vamos entender por experiência perceptiva enganosa, aquela em que as coisas não se apresentam ao sujeito como na experiência verídica, embora seja indistinguível do ponto de vista do sujeito da experiência verídica.

A tese da indistinguibilidade costuma motivar o seguinte argumento cético. Já que não é possível distinguir uma experiência verídica de uma não verídica, então não temos como defender que as razões adquiridas nas experiências verídicas são melhores do que as adquiridas no caso de experiências enganosas. Isso porque o sujeito não é capaz de identificar as origens de suas razões. Para saber se tais razões são resultados de experiências perceptivas verídicas, "o sujeito deveria ser capaz de excluir a hipótese do erro no momento da experiência" (STROUD, 1984, p. 3). Como as experiências perceptivas verídicas não diferem subjetivamente das experiências enganosas, o sujeito parece não ter como excluir a hipótese do erro. A posição de Stroud parece apontar para um beco sem saída. Contudo, ainda nos cabe perguntar: será que mesmo sendo indistinguíveis subjetivamente, tais experiências possuem significados epistêmicos correspondentes? As razões que são fornecidas pelo mundo ao sujeito na experiência verídica, para a justificação de crenças empíricas, possuem o mesmo significado epistêmico das razões fornecidas pela experiência enganosa?

A ideia defendida por disjuntivistas como McDowell é de que, mesmo sendo subjetivamente indistinguíveis, experiências verídicas e enganosas não partilham significados epistêmicos correspondentes. ${ }^{2}$ Por outro lado, filósofos como Burge $(2005,2011)$, que consideram as explicações das ciências cognitivas na formação de crenças, defendem a ideia

\footnotetext{
${ }^{1}$ Vamos traduzir a expressão "the highest common fator" usada por John McDowell como denominador comum. ${ }^{2}$ Vale salientar que Byrne e Logue (2008), (2009) e Haddock e Macpherson (2008) distinguem o disjuntivismo em epistemológico e metafísico ou de caráter fenomenal. No âmbito metafisico destacam-se Hinton (1967), (1973), Snowdon (1981), (1990) e Martin (1997), (2002), (2004), (2006). A ideia do disjuntivismo metafísico é de que mesmo sendo fenomenalmente indistinguíveis, experiências verídicas e não verídicas diferem fundamentalmente em tipo. Em nosso trabalho vamos considerar o disjuntivismo de McDowell, já que o debate trata diretamente de sua posição.
} 
de que existe um denominador comum implicado entre experiências verídicas e experiências enganosas; com isso, é possível dizer que possuem o mesmo valor epistêmico. Burge (2011, p. 43) sustenta tal tese afirmando que "a ciência da percepção é capaz de demonstrar que o estado mental de $\mathrm{X}$ envolvido em uma determinada experiência perceptiva verídica $\Phi$ é o mesmo de uma experiência enganosa $\Phi ”$. McDowell $(2010,2013)$ procurou responder a Burge afirmando que existe uma diferença entre a dimensão epistêmica e a dimensão das ciências cognitivas, e defendeu a tese de que o disjuntivismo é compatível com a ciência da percepção. ${ }^{3}$

A conversa entre Burge e McDowell para saber se o disjuntivismo é compatível ou não com as ciências cognitivas nos puxa para outra questão: pode a epistemologia ser determinada pelas ciências cognitivas? Filósofos como Burge, com motivações naturalistas, acreditam que as ciências cognitivas podem desempenhar papel relevante na história de como as nossas crenças empíricas são formadas. ${ }^{4}$ Por isso, a epistemologia deve ser entendida no vocabulário das ciências cognitivas. Burge com tal tese adota em epistemologia uma posição confiabilista sobre crenças. Já McDowell defende que experiências perceptivas de seres racionais são de outra natureza; para ele, experiências perceptivas de seres humanos fornecem razões para justificar crenças empíricas, e tais razões são acessíveis internamente, do ponto de vista do sujeito possuidor de capacidades racionais. McDowell pensa que as ciências cognitivas não podem determinar a epistemologia, já que descrevem a cognição em terceira pessoa. Para ele existe um domínio epistemológico, que difere da inteligibilidade explicativa das ciências cognitivas. No presente trabalho me coloco ao lado de McDowell e defendo a tese (i) do disjuntivismo epistemológico e (ii) de que as ciências cognitivas não podem determinar a epistemologia.

Para desenvolver o presente artigo, pretendo apresentar: (i) a posição disjuntivista de McDowell; (ii) a objeção de Burge ao disjuntivismo; (iii) a resposta de McDowell às objeções de Burge e (iv) argumento, nos termos de McDowell, que a epistemologia não pode ser determinada pelas ciências cognitivas.

\footnotetext{
3 Para evitar confusões conceituais, de nomenclatura em nosso trabalho, tomaremos ciências cognitivas, psicologia cognitiva, ciência da percepção como equivalentes. Mas sempre usaremos ciência da percepção ou ciências cognitivas.

4 Temos também o naturalismo defendido por Quine (1980, p. 143) que diz afirma que "a epistemologia deve estar contida nas ciências naturais, como um capítulo da psicologia".
} 


\title{
MAPEANDO O DISJUNTIVISMO EPISTEMOLÓGICO DE MCDOWELL
}

McDowell apresenta uma versão do seu disjuntivismo no texto "Criteria, defeasibility, and knowledge" (1982). Neste McDowell procura abordar (i) o problema das outras mentes; (ii) uma interpretação de Wittgenstein sobre a questão e (iii) uma versão do seu disjuntivismo epistemológico. Nosso interesse repousa sobre o que McDowell diz sobre (iii).

McDowell acredita que existe uma forte atração pelo argumento cético de que nosso conhecimento do mundo externo não é seguro, porque nossas capacidades perceptivas são falíveis. Tal argumento é sustentado com base na ideia de que às vezes "julgamos as coisas como sendo de certa maneira, quando na verdade não o são" (McDOWELL, 1982, p. 385). O ponto salientado aqui é que podemos nos enganar acerca do que julgamos empiricamente. Isto ocorre porque as coisas que julgamos e acreditamos sobre o mundo quando estamos enganados não diferem das coisas que julgamos e acreditamos quando tudo vai bem. Dessa forma, as razões adquiridas na experiência verídica para justificar crenças empíricas não parecem ser melhores do que as razões obtidas na experiência enganosa. Esse tipo de argumento parece sugerir que crenças empíricas não possuem garantias sólidas para sua justificação racional, ou seja, não temos garantia de que nossas crenças e julgamentos são dignos de confiança.

McDowell acredita que podemos resistir a esse argumento apelando para a tese disjuntivista sobre a experiência perceptiva. Para entendermos o disjuntivismo de McDowell é preciso fazermos alguns esclarecimentos. Vale dizer que a ideia de ver que $p$ é central ao projeto epistemológico de McDowell. ${ }^{5}$ Ver que $p$ é a ideia de que a experiência perceptiva é factiva e epistêmica. Diz ele:

\begin{abstract}
Numa experiência específica na qual alguém não está iludido, o que a pessoa observa (por exemplo, ver) é que as coisas são de tal e tal modo. Que as coisas são de tal e tal modo é o conteúdo da experiência, e também pode ser o conteúdo de um juízo... Mas que as coisas são de tal e tal modo também é, caso não estejamos, iludidos, um aspecto da disposição geral do mundo: é o modo como as coisas são. (McDOWELL, 2005, p. 63).
\end{abstract}

Ver que $p$ é factivo no sentido de que se Y ver que $p$, então $p$ é o caso. É epistêmico nos seguintes casos (i) ao ver que $p, \mathrm{Y}$ adquire razões para acreditar que $p$ e (ii) se $\mathrm{Y}$ ver que

\footnotetext{
${ }^{5}$ Vamos substituir em nosso trabalho "ver que as coisas são de tal e tal modo" por "ver que p".
} 
$p$, então Y está em posição de saber que p. Como diz McDowell (1982, p. 390): “quando alguém está diante de $p$, a obtenção de $p$ contribui para a garantia epistêmica".

Dito isso, podemos voltar ao argumento disjuntivista elaborado por McDowell a fim de resistir aos resultados céticos do argumento falibilista. McDowell sugere que a experiência de Y de ver que tal e tal é o caso, isto é, ver que $p$, pode ser "ou mera aparência de que tal e tal é o caso ou o fato de que tal e tal é o caso, fazendo-se perceptivamente manifesto a alguém" (McDOWELL, 1982, p. 386). O que o sujeito tem na experiência enganosa é uma mera aparência: as coisas não são como se apresentam ser (ilusão) ou não existe nada para ser percebido (alucinação). No caso da experiência verídica, o que se manifesta ao sujeito é um fato, um aspecto perceptível do mundo, é a própria disposição da realidade. McDowell quer com tal posição negar a tese de que a experiência perceptiva verídica e a experiência enganosa partilham o mesmo significado, porque entende que no caso da experiência verídica obtemos garantias conclusivas para crenças e julgamentos empíricos sobre o mundo.

É o que McDowell defende também no texto "Singular thought and the extent of inner space" (1986). Nesse artigo o disjuntivismo é usado para resistir à estratégia cética de Descartes. Ao colocar o mundo externo sob suspeita, Descartes (1973, p. 102) parece garantir a certeza do "cogito, do eu penso". A questão é que ao garantir a certeza do eu penso, ele perde o mundo externo. O máximo que Descartes pode oferecer como premissa para seu argumento de que não perdemos o mundo é a ideia de que podemos conhecer o mundo por introspecção. O que ainda é uma posição insatisfatória. McDowell acredita que com tal posição Descartes “introduz uma cisão entre o mundo interno e o mundo externo, nos jogando em um cenário de ceticismo" (McDOWELL, 1986, p. 239). A questão é: o que garante o engate da mente com o mundo, se o que podemos saber são coisas sobre os nossos próprios estados mentais? Se o que podemos saber é assegurado somente por introspecção, não temos como saber se nossa experiência é constrangida pelo mundo. Perante a imagem cartesiana McDowell (1986, p. 242) considera que "podemos tomar a experiência disjuntivamente, como constituída pelo fato de que as coisas se apresentam de tal e tal modo ou pelo fato de que as coisas meramente parecem ser o caso".

A tentação filosófica é tomar o cenário cartesiano da falibilidade como premissa para o argumento de que não podemos nunca ter certeza das coisas que acreditamos saber sobre o mundo. É justamente esse tipo de argumento que McDowell tenta bloquear com a posição disjuntivista. McDowell reconhece que existem casos em que nos enganamos sobre o que 
sabemos sobre o mundo, mas isso não pode obscurecer a ideia de que na experiência perceptiva verídica o sujeito está de posse de um estado perceptivo que fornece garantias para sua crença empírica. Diz ele (2011, p. 41): “a capacidade perceptiva racional é a capacidade, não somente para saber certos tipos de coisas sobre o ambiente, mas uma ocasião em que alguém sabe alguma coisa de tipo relevante, através do exercício da capacidade em questão, saber como é que sabe". Aqui é a ocasião de considerar que quando alguém sabe que $p$, quando percebe ser o caso, então alguém sabe que percebe que $p$.

\section{OBJEÇÕES DE BURGE AO DISJUNTIVISMO}

As objeções de Burge se ancoram no seguinte pensamento. Se o interesse filosófico é no papel que a experiência perceptiva consciente desempenha em fornecer ao sujeito da experiência informações sobre o ambiente, então deveríamos olhar para as explicações da ciência da percepção sobre como ocorre tal processo. Se a ideia de estados perceptivos com conteúdo representacional é essencial ao modelo descritivo da ciência, então a postulação de estados representacionais é justificada por seu poder explicativo.

Burge (2011, p. 66) acredita que "os estados perceptivos humanos devem ser classificados de acordo com os critérios da ciência da percepção". Ele acredita que a ciência da visão opera na base de um paradigma explicativo, que faz atribuições de estados perceptivos, com conteúdo representacional específico e condições de veracidade, fundamentais a sua explicação. Por isso a ciência da visão é capaz de fornecer explicações seguras na forma como adquirimos informações do ambiente. Diz Burge (2005, p. 09):

A psicologia da percepção, particularmente, visão, tem se tornado uma ciência séria. Apresenta resultados bem estabelecidos e aplica com sucesso os métodos da matemática. Não existe nenhuma boa razão para duvidar que tal ciência não forneça insights não somente nos mecanismos da percepção, como também em aspectos de sua natureza.

Por apresentar resultados bem estabelecidos e aplicar com sucesso os métodos da matemática, a ciência da percepção pode explicar com maior sucesso o funcionamento do nosso mecanismo perceptivo nos casos verídicos e enganosos. As explicações causais oferecidas pela ciência devem nos levar a aceitar o fato de que estados perceptivos de mesmo tipo fundamental podem ser gerados em casos de experiências verídicas e experiências enganosas. Burge (2005, p. 22) chama tais explicações de "princípio proximal” (proximality 
principle). É importante tratar desse princípio, pois Burge sugere que o disjuntivismo é incompatível com a ciência da percepção com base nele.

\section{BURGE E O PRINCÍPIO PROXIMAL (PROXIMALITY PRINCIPLE)}

Burge elabora sua ideia de principio proximal (proximality principle) no artigo "Disjunctivism and perceptual psychology" (2005). Ele diz que o primeiro objetivo de sua teoria é explicar "a estrutura geral da percepção humana e animal” (BURGE, 2005, p. 13). A teoria deve incorporar "o que é conhecido sobre os mecanismos explicativos de correção e incorreção do sistema perceptivo" (p. 21). A ideia de Burge é de que estados perceptivos não são somente o resultado final de uma série de processos. Ele acredita que estados perceptivos acontecem em diversos estágios dentro desse processo (p. 21). Muitos dos estados representacionais atribuídos a seres humanos são pré-teóricos, por isso não podemos considerar como estados perceptivos. Burge também quer fazer uso em sua metodologia dos objetos que são familiares ao senso comum e a introspeção informada, porque acredita que “em seres humanos grande parte das percepções são acessíveis à consciência” (p. 21).

Burge (2005, p. 22) acredita que deve ser traçada uma linha entre "percepção (estados ou conteúdo representacionais) e processos e princípios". Estes últimos não estariam disponíveis aos indivíduos de forma consciente. Contudo, Burge não pretende fornecer explicações com base nessa distinção; a questão é apenas mostrar que a teoria vai tratar diretamente da visão e dos estados visuais dos indivíduos. A teoria de acordo com Burge está preocupada em explicar estados que são reconhecidamente dos sujeitos, e não dos subsistemas envolvidos (p. 22).

O segundo ponto abordado por Burge é o seguinte. O objetivo da ciência é identificar processos e princípios por meio dos quais o sistema perceptivo extrai, converte e processa informação geradas pela estimulação sensorial, em ordem de produzir estados perceptivos que representem o ambiente. O papel da ciência é descobrir as leis de acordo com as quais o sistema perceptivo opera, assim como entender como o aparato sensorial é acionado. As leis em questão descreveriam de que forma são produzidos os estados representacionais por meio do (i) estímulo proximal e (ii) dos estados psicológicos antecedentes do indivíduo. Assim, as leis formuladas pela ciência explicariam como os estados perceptivos representacionais são gerados pelo sistema perceptivo, considerando que "as causas proximais e estados 
psicológicos antecedentes do sujeito fossem mantidos constantes, e considerando que não exista nenhum mau funcionamento relevante no sistema perceptivo" (BURGE, 2005, p. 22).

Dado que a estimulação proximal pode ser especificada de forma a não levar em consideração nenhum ambiente particular, "o mesmo tipo de estado perceptivo representacional pode ser produzido em casos de experiência perceptiva verídica e experiência enganosa" (BURGE, 2005, p. 22). Burge acredita que "se um dado objeto é visto, ou duplicado, ou é produzido em uma ilusão contextual indiscernível, as transformações no registro de luz dispostas na representação perceptiva são, para propósitos psicológicos, de tipo idênticas" (p. 46). Burge acredita que o princípio proximal está implícito nas explicações causais da ciência da percepção. Entende que, se tivermos os antecedentes totais do estado psicológico dos indivíduos e do sistema, “os estímulos proximais produzirão um tipo determinado de estado perceptivo representacional, uma vez que não exista nenhum mau funcionamento ou interferência no sistema" (BURGE, 2005, p. 22).

Com isso Burge defende que os cientistas podem estudar os princípios de enviesamento e estados representacionais separadamente das condições do ambiente. A ideia é de que "os conteúdos perceptivos representacionais, portanto, estados perceptivos, não são individuados puramente com base nos referentes do ambiente" (BURGE, 2005, p. 23). Burge acredita que é uma questão empírica "se o sistema representacional do indivíduo tem disposição para considerar o referente como tipo representacional diferente ou semelhante... é uma questão empírica se as representações que são tratadas como percepção de propriedades semelhantes, são de fato semelhantes" (p. 23).

Em resumo, Burge acredita que o disjuntivismo é incompatível com o conhecimento científico da percepção, porque a psicologia da percepção é capaz de mostrar que as experiências perceptivas verídicas e enganosas partilham conteúdos representacionais de mesmo tipo. Isto porque o foco da ciência da percepção é no fator comum implicado em tais experiências, e o disjuntivismo não tem nada a dizer de interessante sobre o funcionamento do sistema perceptivo.

Estados perceptivos simplesmente dependem para serem formados (i) dos registros da estimulação proximal, (ii) dos antecedentes psicológicos e estados físicos dos indivíduos e (iii) das leis quase determinísticas de transição entre os registros da estimulação proximal e os estados perceptivos que são formados. Por isso Burge defende que o fator envolvido no (1) caso das percepções verídicas, (2) caso de percepções indiscerníveis de diferentes objetos e (3) caso de ilusões ordinárias é o mesmo. Os casos de (1)-(3) começam a partir do mesmo 
estímulo proximal, e somente a ciência da percepção pode distinguir os fatores que não são partilhados nas experiências citadas.

A questão é: se nossos mecanismos perceptivos podem produzir representações verídicas e representações enganosas de mesmo tipo, como podemos saber que não estamos enganados, quando acreditamos em alguma coisa ou julgamos empiricamente? Burge conta uma história científica sobre como nosso sistema perceptivo produz crenças empíricas confiáveis. Primeiro, ele considera que os conteúdos representacionais e princípios de enviesamento "são o que são por causa do padrão confiável de interação do ambiente, no processo evolutivo ontogenético, com o sistema perceptivo" (BURGE, 2005, p. 23). Nesse caso, os nossos julgamentos e crenças empíricas são confiáveis, porque o sistema perceptivo na maior parte dos casos produz crenças verdadeiras. Uma boa razão para considerar esse fato é a interação de sucesso do ser humano com o ambiente, que permitiu a sobrevivência da espécie.

Burge, com tal posição, se filia à tese naturalista de Quine, que defende que

A epistemologia, ou algo que ela se assemelhe, encontra seu lugar simplesmente como um capítulo da psicologia e, portanto, da ciência natural. Ela estuda um fenômeno natural, a saber, um sujeito humano físico. Concede-se que esse sujeito humano recebe uma certa entrada experimentalmente controlada - certos padrões de irradiação em variadas frequências, por exemplo - e no devido tempo o sujeito fornece como saída uma descrição do mundo externo tridimensional e sua história... uma visível diferença entre a antiga epistemologia e o empreendimento epistemológico dentro desse novo quadro psicológico é que agora temos toda liberdade de fazer uso da psicologia empírica. (QUINE, 1980, p. 164).

Podemos dizer que Burge adota uma tese naturalista, porque, como Quine, defende que a epistemologia deve ser um capítulo da psicologia, ou seja, das ciências. Nesse sentido, a epistemologia como centrada na ideia de conhecimento não poderia fornecer grandes contribuições sobre a questão da experiência. Seria mais promissor a epistemologia ser anexada às ciências. Estão associados à tese naturalista filósofos como Daniel Dennett, Hilary Kornblith e outros. A questão é verificarmos se podemos defender uma inteligibilidade epistemológica que não seja reduzida à linguagem das ciências cognitivas. 


\title{
RESPOSTA DE MCDOWELL A BURGE
}

McDowell (2013a) em "Tyler Burge on disjunctivism (II)" diz que Burge não consegue identificar os disjuntivismos em jogo, um sobre a epistemologia da garantia de crenças empíricas e outro sobre o pensamento singular. McDowell (2013a, p. 260) acredita que Burge oferece uma descrição que unifica os dois disjuntivismos, por isso não consegue oferecer uma resposta satisfatória às duas posições envolvidas.

McDowell (2013a, p. 359) fornece uma formulação básica do seu disjuntivismo epistemológico:

\begin{abstract}
$\mathrm{Na}$ experiência perceptiva o sujeito tem a aparência de alguma coisa como sendo de certo modo no ambiente. Em alguns casos (bons casos), a experiência manifesta ao sujeito as coisas como sendo deste modo; em outros (casos ruins), a aparência de que as coisas são de tal e tal modo são meras aparências. Uma experiência em que a aparência das coisas são mera aparência pode ser tal que o sujeito não pode falar que não é uma experiência do primeiro tipo. $\mathrm{O}$ ponto do meu disjuntivismo epistemológico é que indiscriminabilidade não implica correspondência em significado epistêmico.
\end{abstract}

A tese de McDowell com seu disjuntivismo é de que as experiências indistinguíveis subjetivamente não partilham o mesmo significado epistêmico nas garantias que fornecem para julgamentos e crenças empíricas. Portanto, McDowell rejeita a seguinte ideia: "se alguém sabe alguma coisa sobre o ambiente através da experiência, deve ser em virtude de alguma coisa adicional à própria experiência” (2013a, p. 362). Aqui McDowell já começa a dar sinais da sua rejeição a explicações científicas.

O ponto envolvido no disjuntivismo de McDowell é que nos bons casos, quando as coisas vão bem na operação das capacidades perceptivas de seres racionais, o sujeito está em um estado perceptivo que presentifica características do mundo, que fornece garantias conclusivas para a crença empírica em questão. Podemos pensar no caso de uma experiência em que o sujeito é capaz de saber que existe um computador sobre a mesa e uma experiência em que meramente parece ter um computador sobre a mesa. Nesse caso, temos uma experiência que é indistinguível subjetivamente da outra, já que o sujeito nos dois casos tem um estado representacional com o mesmo conteúdo. A questão é que quando o sujeito está diante de um computador localizado a sua frente sobre a mesa, está em posição de saber, que pode expressar julgamentos da forma, tem um computador sobre a mesa. Aqui a experiência fornece garantias conclusivas para a crença de que existe um computador sobre a mesa. 
McDowell rejeita a posição de Burge de que o papel explicativo das ciências cognitivas determine como os estados perceptivos devam ser classificados, em relação a seu significado epistêmico. McDowell alega que o disjuntivismo exige uma concepção diferente de epistemologia, já que "a classificação explicativa que é fundamental para propósitos epistemológicos não coincide com os propósitos explicativos que são fundamentais às ciências cognitivas" (McDOWELL, 2013a, p. 262). Por isso, nega que o disjuntivismo seja incompatível com as ciências cognitivas. McDowell reconhece que podem ser ditas coisas verdadeiras sobre as experiências verídicas e enganosas, se é isso que se entende por denominador comum. O que McDowell (2013a, p. 262) nega "é que as experiências partilhem significados semelhantes em nível epistêmico mais fundamental".

McDowell acredita que uma forte razão para Burge rejeitar o disjuntivismo é a sua ideia de que é incompatível com as ciências cognitivas. McDowell diz que Burge está certo sobre as coisas que diz sobre as ciências cognitivas. Para ele ao nível da classificação que é fundamental aos propósitos explicativos das ciências cognitivas, "as experiências verídicas e enganosas podem ser agrupadas como tendo o mesmo tipo de conteúdo representacional" (McDOWELL, 2013b, p. 6). O que McDowell nega é a tese de que isto gere incompatibilidade entre o disjuntivismo e as ciências cognitivas.

Vejamos o que ele diz a respeito do ponto de Burge sobre as ciências cognitivas:

O tipo de teoria que Burge tem em mente objetiva explicar como o sistema perceptivo funciona da forma como funciona. Uma explicação cognitivo-científica de como trabalha um sistema perceptivo mostra em termos computacionais como, dos registros de estímulos sensoriais (estimulação dos nervos da retina pela luz), o sistema gera representações, culminando em representações de circunstâncias que são percebidas pelos indivíduos. (McDOWELL, 2013b, p. 6).

O ponto envolvido em tal posição é de que as ciências cognitivas podem descrever como os estados perceptivos e as representações dos indivíduos são produzidos. Certamente existem diferenças entre percepções verídicas e enganosas que podem ser explicadas pelas ciências cognitivas. Se a experiência perceptiva do sujeito é enganosa, significa que o sistema perceptivo não está funcionando adequadamente, e as ciências cognitivas podem explicar, porque o sistema perceptivo não funciona corretamente. Por isso, Burge pensa que a epistemologia deve ser descrita nos termos das ciências cognitivas.

McDowell acredita que as explicações computacionais fornecidas pelas ciências cognitivas sobre o funcionamento do sistema perceptivo é externa à inteligibilidade que 
encontramos em estados perceptivos de sujeitos racionais em primeira pessoa. McDowell reconhece que as ciências cognitivas podem explicar aspectos do caráter representacional dos estados perceptivos, que não discrimina entre experiências perceptivas verídicas e experiências enganosas com conteúdo correspondente (McDOWELL, 2013b, p. 9). O trabalho de distinguir as experiências perceptivas verídicas das experiências enganosas em termos epistemológicos é externo às explicações científicas.

Para McDowell (2013b, p. 10), "Burge não é capaz de perceber que existem dois modos de inteligibilidade". As ciências cognitivas explicam com sucesso o caráter representacional dos estados perceptivos, mas não podem ser consideradas como única forma de compreender e explicar as experiências perceptivas. As explicações cientificas não fazem justiça ao significado epistêmico das experiências perceptivas dos sujeitos em primeira pessoa na sua relação com o mundo. Claro que podemos explicar os estados perceptivos em termos computacionais como Burge defende, mas esse modo não exclui o entendimento da experiência perceptiva em seu significado epistêmico. Sabemos que nossas capacidades perceptivas são falíveis, pois podemos nos enganar sobre as coisas em que acreditamos e julgamos acerca do mundo. Mas, na experiência verídica, se o sujeito tem certo aspecto do mundo presente a ele, então está em posição, que não deixa aberta nenhuma possibilidade, de que o mundo não esteja disponível a ele. Nesse caso, o sujeito tem uma garantia conclusiva para acreditar ou julgar que um aspecto do mundo está diante dele, de tal e tal modo.

McDowell (2013b, p. 10) acredita que esses dois modos de inteligibilidade, o das ciências cognitivas e o epistemológico, não competem entre si. Quando explicamos os estados perceptivos como resultados de diferentes respostas ao ambiente, mediado pelas informações fornecidas pelos inputs sensoriais, a inteligibilidade que encontramos é revelada pela explicação cognitivo-científica. As representações subindividuais não são atos da capacidade racionais do sujeito para conhecer o mundo. ${ }^{6}$ Contudo, podemos explicar os mesmos estados perceptivos como atos da capacidade de sujeitos racionais. Quando fazemos isso entendemos “a experiência perceptiva em seu significado epistemológico" (McDOWELL, 2013b, p. 10).

\footnotetext{
${ }^{6}$ Para Dennett os sistemas perceptivos subindividuais, como sistemas computacionais engenharias sintáticas e não semânticas.
} 


\section{PODEM AS CIÊNCIAS COGNITIVAS DETERMINAR A EPISTEMOLOGIA?}

Outro argumento que podemos oferecer contra a tese de que as ciências cognitivas podem determinar a epistemologia é um argumento fenomenológico. Primeiro, vejamos a descrição naturalista de Quine (1976, p. 228) da experiência:

Eu sou um objeto físico situado em um mundo físico. Algumas das forças desse mundo físico colidem contra minha superfície. Raios de luz atingem minhas retinas; moléculas bombardeiam meus tímpanos e as pontas de meus dedos. Eu revido, emanando ondas concêntricas de ar. Essas ondas tomam a forma de uma torrente de discurso sobre mesas, pessoas, moléculas, raios de luz, retinas, ondas de ar, números primos, classes infinitas, alegria e sofrimento, bem e mal.

$\mathrm{Na}$ descrição de Quine, podemos identificar a inteligibilidade das explicações científico-cognitivas, como defendida por Burge. Tal descrição não leva em consideração o significado epistêmico da experiência perceptiva. Outra característica da descrição quiniana da experiência é que ela é realizada em terceira pessoa, a experiência, nesse caso, não é entendida tal como é do ponto de vista do sujeito.

Parece estranho supor que alguém descreva sua experiência do mundo como Quine sugere, pois na relação epistêmica imediata com o mundo o sujeito não percebe raios de luz atingindo a retina. $\mathrm{Na}$ experiência os indivíduos percebem o mundo com significado epistêmico, o que o sujeito vê na sua ralação com o mundo são coisas como esta garrafa, este cachorro, que o computador está sobre a mesa, que o livro é vermelho e que o gato está no sofá, etc.

Este mundo com significado epistêmico é o que o indivíduo racional percebe na experiência em primeira pessoa. Nesse caso, entender a experiência disjuntivamente, ou seja, com significado epistêmico é conceber que na experiência o sujeito pode estar diante de um aspecto do mundo, e adquirir garantias conclusivas para sua crença empírica, ou pode meramente parecer que as coisas se manifestam como sendo de tal e tal modo, em que a garantia não é conclusiva. Embora as experiências sejam subjetivamente indistinguíveis, o valor epistêmico da experiência verídica é diferente da experiência enganosa. O ponto de McDowell contra Burge é que as experiências verídicas e enganosas diferem epistemicamente em significado e tipo.

O argumento pode ser formulado na forma válida do Modus tollens: 
Se a única inteligibilidade explicativa do sistema perceptivo é a das ciências cognitivas, então temos apenas descrições da experiência em terceira pessoa. Não é o caso que temos apenas descrições da experiência em terceira pessoa, portanto não é o caso que a única inteligibilidade explicativa do sistema perceptivo seja a das ciências cognitivas. Vimos que McDowell defende uma noção de experiência perceptiva do mundo em primeira pessoa, com significado epistêmico. Aqui o mundo se apresenta ao sujeito como sendo de tal e tal modo. As ciências cognitivas descrevem a experiência perceptiva em termos da entrada de onda de luz na retina, que é uma descrição em terceira pessoa. Contudo, seres racionais não percebem ondas de luz na retina, mas sim o mundo como sendo de tal e tal modo. Como diz Rödl (2007, p. 157-158): “quando sei que $p$, quando percebo ser o caso, então sei que eu percebo que $p$ ".

\section{CONSIDERAÇÕES FINAIS}

Burge acredita que a epistemologia deve ser entendida no vocabulário das ciências cognitivas, o que o coloca ao lado de filósofos naturalistas como Quine. A principal objeção fornecida contra o disjuntivismo é de que ele é incompatível com as ciências cognitivas. Por outro lado, McDowell argumenta que o disjuntivismo exige uma diferente concepção de epistemologia, uma que é própria de indivíduos possuidores de capacidades racionais. Isso porque McDowell acredita que experiências perceptivas verídicas e experiências enganosas são indistinguíveis subjetivamente, mas diferem em significado epistêmico. $\mathrm{Na}$ experiência verídica, um aspecto do mundo se manifesta ao sujeito como sendo de tal e tal modo, e na experiência enganosa meramente as coisas parecem ser de tal e tal modo.

A discussão sobre o disjuntivismo nos levou para a questão de saber se as ciências cognitivas podem determinar a epistemologia. Filósofos como Quine, Dretske, Kornblith, Burge e Dennett acreditam que a epistemologia deve ser reduzida às explicações das ciências cognitivas. Se as ciências cognitivas descrevem as experiências verídicas e as experiências enganosas como sendo de mesmo tipo, como sabemos que não estamos enganados sobre as coisas em que acreditamos empiricamente, tal como proposto pelo cenário cético? Tais filósofos acreditam que o sistema perceptivo, no processo evolutivo, se caracterizou por produzir mais crenças verdadeiras do que crenças enganosas, por isso podemos confiar em nossas crenças e julgamentos empíricos.

McDowell rejeita essa posição confiabilista, pois acredita que as razões, ou seja, as garantias fornecidas pelo mundo devem ser acessadas em primeira pessoa. O sujeito racional 
deve ser capaz de acessar as razões fornecidas pelo mundo, a fim de justificar as suas crenças empíricas. O confiabilismo deixa a porta aberta para a entrada do ceticismo, uma vez que as crenças empíricas dependem de fatores externos à inteligibilidade do sujeito. Nesse caso, as minhas crenças podem ser produzidas simplesmente por inputs de um computador ligado ao meu cérebro, e este é um resultado insatisfatório do ponto de vista epistemológico.

Aqui tentamos apenas esboçar uma resposta à questão se as ciências cognitivas podem determinar a epistemologia. O problema permanece em aberto. Apenas pretendemos apresentar o debate de forma breve neste artigo. Questões paralelas que esbarram neste debate, que foram apenas mencionadas aqui, podem ser importantes para uma resposta adequada à questão, como o debate entre Thomas Nagel e Daniel Dennett sobre se a consciência pode ser compreendida em termos evolutivos ou não.

\section{REFERÊNCIAS}

BONJOUR, Laurence. Against naturalized epistemology. Midwest Studies in Philosophy, v. 19, p. 283-300, 1994.

BURGE, Tyler. Perceptual entitlement. Philosophy and Phenomenological Research 67 (3), p. 503-548, 2003.

BURGE, Tyler. Disjunctivism and perceptual psychology. Philosophical Topics 33 (1), p. 1$78,2005$.

BURGE, Tyler. Disjunctivism again. Philosophical Explorations 14 (1), p. 43-80, 2011.

BURGE, Tyler. Origins of objectivity. Oxford University Press, 2010.

BURGE, Tyler. Cognition through understanding: self-knowledge, interlocution, reasoning, reflection. Oxford University Press, 2013.

DESCARTES, René. Meditações. Trad. J. Guinsburg e Bento Prado Jr. São Paulo: Abril Cultural, 1973. p. 93-150. (Os pensadores, v. XV).

DENNETT, Daniel. From bacteria to Bach and Back: the evolution of minds. W. W. Norton \& Company, 2017.

DENNETT, Daniel. Toward a cognitive theory of consciousness. In: DENNETT, Daniel. Brainstorms. Montgomery, VT: Bradford Books, 1978, p. 149-173.

DODD, Dylan; ZARDINI, Elia (ed.). Scepticism and perceptual justification. Oxford University Press, 2014. 
DRETSKE, Fred. Naturalizing the mind. Cambridge, Mass: The MIT Press, 1995.

DRETSKE, Fred. Perception, knowledge and belief. Cambridge: Cambridge University Press, 2000.

KORNBLITH, Hilary. Naturalizing epistemology (ed.). 2nd edition. MIT Press, 1994.

KORNBLITH, Hilary. Knowledge and its place in nature. Oxford University Press, 2002.

McDOWELL, John. Can cognitive science determine epistemology?: first lecture delivered by Professor John H. McDowell at the 2013. In: Agnes Cuming Lectures and Seminar, hosted by the UCD School of Philosophy, 2013b.

McDOWELL, John. Singular thought and the extent of inner space (ed.). Subject, thought and context. Oxford: Clarendon Press, 1986. [Reprinted in his Meaning, knowledge, and reality. Cambridge, MA: Harvard University Press, 1998].

McDOWELL, John. The content of perceptual experience. Philosophical Quarterly 44 (175), 1994. p. 190-205. [Reprinted in a slightly different form in McDowell 1998d, p. 341$358]$.

McDOWELL, John. Mente e mundo. Tradução de João Vergílio Gallerani Cuter; ensaio introdutório Hilan Bensusan. Aparecida, SP: Ideias \& Letras, 2005. [Mind and World. Cambridge, MA: Harvard University Press,1994].

McDOWELL, John. 'Criteria, defeasibilty, and knowledge'. Proceedings of the British Academy, 68, p. 455-457, 1982. [Reprinted in his Meaning, knowledge, and reality, Cambridge, MA: Harvard University Press, 1998.]

McDOWELL, John. Tyler Burge on disjunctivism. Philosophical Explorations 13 (3), p. 243-255, 2010.

McDOWELL, John. Tyler Burge on disjunctivism (II), Philosophical Explorations, 16 (3), p. 259-279, 2013a.

McDOWELL, John. Perception as a capacity for knowledge. Marquette University Press, 2011.

NAGEL, Thomas Mind and cosmos: why the materialist neo-Darwinian conception of nature is almost certainly false. Oxford New York: Oxford University Press, 2012.

NAGEL, Thomas. Visão a partir de lugar nenhum. São Paulo: Martins Fontes, 2004.

QUINE, W.V. Epistemologia naturalizada. Tradução Oswaldo Porchat de Assis e Andréa Maria de Campos Loparic. São Paulo: Abril Cultural, 1980. (Os Pensadores).

QUINE, W.V. Ways of paradox. New York: Random House; second edition, enlarged, Cambridge, MA: Harvard University Press, 1976. 
RÖDL, Sebastian. Self-consciousness. Cambridge, MA: Harvard University Press, 2007. STROUD, Barry. The significance of philosophical scepticism. Oxford University Press, 1984.

WILLIAMSON, Timothy. Is knowing a state of mind? Mind, 104, n. 414, p. 533-565, 1995.

WILLIAMSON, Timothy. Knowledge and its limits. Oxford: Oxford University Press, 2000 .

WILLIAMSON, Timothy. The philosophy of philosophy. Oxford: Blackwell, 2007. 